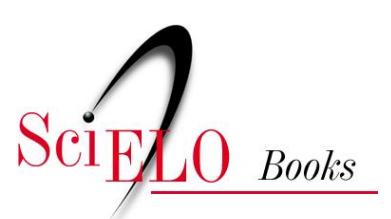

\title{
2. Histórico do controle da transmissão vetorial e situação epidemiológica atual
}

\author{
Antonio Carlos Silveira \\ Emanuel Martins
}

\section{SciELO Books / SciELO Livros / SciELO Libros}

SILVEIRA, AC., and MARTINS, E. Histórico do controle da transmissão vetorial e situação epidemiológica atual. In: GALVÃO, C., org. Vetores da doença de chagas no Brasil [online]. Curitiba: Sociedade Brasileira de Zoologia, 2014, pp. 10-25. Zoologia: guias e manuais de identificação series. ISBN 978-85-98203-09-6. Available from SciELO Books $<\underline{\text { http://books.scielo.org }>\text {. }}$

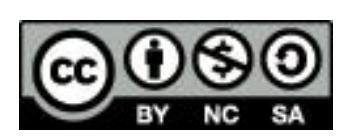

All the contents of this chapter, except where otherwise noted, is licensed under a Creative Commons Attribution-Non Commercial-ShareAlike 3.0 Unported.

Todo o conteúdo deste capítulo, exceto quando houver ressalva, é publicado sob a licença Creative Commons Atribuição Uso Não Comercial - Partilha nos Mesmos Termos 3.0 Não adaptada.

Todo el contenido de este capítulo, excepto donde se indique lo contrario, está bajo licencia de la licencia Creative Commons Reconocimento-NoComercial-CompartirIgual 3.0 Unported. 


\title{
2. Histórico do controle da transmissão vetorial e situação epidemiológica atual
}

\author{
(Antonio Carlos Silveira \& Emanuel Martins)
}

"É mesmo crença universal, em nossos sertões, que o hematophago, na phase alada, vem do exterior para os domicílios, attrahido pela luz. Não sabemos si assim é, porque só uma vez nos foi possível observar a chegada de um conorrhinus adulto no interior de nosso laboratório. Será o barbeiro um insecto silvestre, como querem os naturaes das zonas onde existe, ou ter-se-á, por uma adaptação biológica atravez do tempo, tornado-se exclusivamente domiciliario?"

(Carlos Chagas, Conferência realizada na Sociedade de Medicina e Cirurgia de Minas Gerais, em Belo Horizonte, na sessão solene de 30 de julho de 1911).

\section{Introdução}

Carlos Chagas antevia a necessidade e, mais que isso, exigia providências, para que se fizesse o controle da transmissão vetorial da doença recém descoberta e por ele descrita, quando dizia que "... a iniciativa de medidas sanitárias justifica-se, sem duvida, em considerações bem mais elevadas: é o futuro de um grande povo que se deverá zelar; são deveres de humanidade e patriotismo que devem actuar no espírito progressista dos homens de estado; é a vida humana, é progresso material, o aperfeiçoamento de uma raça que degenera... " (Chagas 1911). Por isso mesmo, de inicio, a maior parte dos estudos, alguns deles conduzidos pelo próprio Carlos Chagas ou sob seu estímulo, estiveram focados na perspectiva de sua prevenção, desde que ele mesmo considerava "difícil o tratamento da parasitose".

Carlos Chagas suspeitou também, desde os primórdios de sua descoberta, que a transmissão da doença devesse "transcender os sertões de Minas Gerais". Já em 1911 afirmava, em conferência proferida na Academia Nacional de Medicina que "... a extensão e intensidade endemica serão inmensas em algumas zonas, especialmente entre as populações ruraes".

De fato, à medida que se foi acumulando conhecimento, percebeu-se que a distribuição dos triatomíneos, vetores ou potencialmente vetores da doença de Chagas, abrange uma amplíssima área, entre os $40^{\circ}$ de latitude norte e $45^{\circ}$ de latitude sul (Jörg 1957, Bonet 1972, Zeledón 1972), com a ocorrência registrada de infecção humana autóctone desde o sul dos Estados Unidos - onde tem sido reportados alguns poucos casos - até a Província de Chubut na Argentina (Marsden 1983, WHO 1991 e 2000, Silveira 1999). Da mesma forma uma grande variedade de espécies de triatomíneos foi sendo conhecida, com maior ou menor importância na transmissão domiciliar da infecção/doença de Chagas. Importância em princípio determinada por sua maior ou menor adaptação ao domicílio. O que, por sua vez, depende do ecletismo alimentar da espécie, das fontes 
peridomésticas ou da oferta existente e, fundamentalmente, de sua antropofilia, ao colonizar ou não o interior da habitação.

Evidentemente que no entendimento do processo de domiciliação dos vetores outras condições influentes devem ser tomadas em conta. A transmissão domiciliar da doença de Chagas é própria de espaços abertos, naturais ou produto da ação antrópica. A intervenção do ser humano sobre o ambiente, algumas vezes predatória, promoveu o deslocamento dos triatomíneos de seus ecótopos silvestres, tendo eles encontrado na moradia humana, quando mal construída ou conservada, e em seu entorno peridomiciliar, condições ideais de abrigo e sobrevivência. A questão de fundo ou a causa primária é então de natureza econômica. A casa vulnerável à infestação pelos vetores é expressão das precárias condições econômicas e de vida das populações sob risco, sobretudo no meio rural.

Por outro lado, a capacidade vetorial das diferentes espécies de vetor depende de alguns de seus atributos, de um maior grau de antropofilia e metaciclogênese (produção de um maior número de formas infectantes de Trypanosoma cruzi), e de um menor tempo entre repasto sanguíneo e dejeção.

No mundo são 148 espécies formalmente descritas de triatomíneos, das quais como vetores especialmente competentes são apontados Triatoma infestans, Rhodnius prolixus, Triatoma dimidiata, Panstrongylus megistus e Triatoma brasiliensis.

No Brasil se está contabilizando atualmente a existência de 65 espécies de triatomíneos (veja capítulo 8), sendo reconhecidas cinco como aquelas que têm, ou tiveram, participação mais relevante na transmissão domiciliar: Triatoma infestans, Triatoma brasiliensis, Triatoma pseudomaculata, Triatoma sordida e Panstrongylus megistus (Silveira et al. 1984).

\section{O controle da transmissão vetorial e sua história}

A criação em 1943 do Centro de Estudos da Fundação Oswaldo Cruz em Bambuí, Minas Gerais, marca a primeira iniciativa institucionalizada de se buscar os meios para o controle da transmissão vetorial da doença de Chagas no país. Diferentes alternativas foram testadas, inicialmente sem muito sucesso. Entre outras, o uso de Dicloro-Difenil-Tricloroetano (DDT) em expurgos domiciliares, inseticida então empregado no controle dos vetores da malária. Em 1947, ensaios de laboratório com um novo inseticida clorado, o Gamexanne P 530 ou hexaclorociclohexano (BHC), haviam mostrado resultados promissores como triatominicida (Busvine \& Barnes 1947). Provas de terreno realizadas no ano seguinte pelos pesquisadores de Bambuí, em Santa Juliana e Água Comprida, municípios do Triângulo Mineiro, comprovaram a alta ação tóxica do isômero gama do BHC para populações domiciliadas de triatomíneos (Dias \& Pellegrino 1948). Esses resultados foram ratificados posteriormente em estudos realizados na Argentina (Romana \& Aballos 1948) e Uruguai (Osimani et al. 1950).

A partir de então se contava com tecnologia simples e comprovadamente eficaz no controle da transmissão vetorial da doença de Chagas. Em 1950 o então Serviço Nacional de Malária (SNM) foi incumbido de realizar aquela que se considera ser a "primeira campanha" de controle da doença 
de Chagas no país. Entre maio de 1950 e setembro de 1951, o chamado “Programa de Profilaxia da Doença de Chagas" alcançou com atividades de pesquisa e borrifação a 74 municípios situados no vale do Rio Grande, na divisa dos estados de Minas Gerais e São Paulo.

Até o ano de 1968, dados acumulados mostram terem sido realizados inquéritos entomológicos em 1.760 municípios do país, dos quais em 1.238 se verificou a existência de triatomíneos domiciliados; e, em 1.096 destes, a presença de exemplares infectados por Trypanosoma tipo cruzi. Desde aquele primeiro "Programa de Profilaxia" até 1972 teriam sido feitos aproximadamente 11 (onze) milhões de expurgos domiciliares com inseticidas de ação residual (BHC) (Marques 1979).

Mesmo que não se tenha feito uma avaliação formal e mais abrangente de todas essas atividades, a julgar pelos resultados colhidos nos dois grandes inquéritos nacionais realizados anos depois, o entomológico (1975-83) (Silveira et al. 1984) e o de soro-prevalência (1975-1980) (Camargo et al. 1984), o impacto havido na transmissão esteve aquém do que seria de se esperar. Em que pese a grande extensão e volume das operações, o que explicaria que as respostas tenham sido pouco consequentes seria a irregularidade das atividades, tanto sua continuidade no tempo, como a contiguidade das áreas onde se interveio. Até então, apesar da grande magnitude da endemia chagásica no país e de sua alta transcendência, a prioridade conferida a seu controle era precária e instável. Outros agravos que, diferentemente da doença de Chagas, se transmitiam em área urbana e de forma epidêmica mereciam absoluta precedência. A pouca aparência clínica da fase aguda e o longo curso crônico da infecção por Trypanosoma cruzi, ademais dos grupos populacionais afetados, quase sempre rurais e economicamente marginais, faziam com que a demanda social pelo seu controle fosse pequena, ou nenhuma. Coube à comunidade científica interessada no tema a demonstração insistente do quanto interessava o controle da doença de Chagas, tanto do ponto de vista humano e social, como o fez Carlos Chagas, quanto do ponto de vista dos benefícios de natureza econômica.

A partir de 1975, com a malária já controlada em extensas áreas do país, especialmente nas regiões sudeste, nordeste e em parte do centro-oeste, os recursos daí excedentes foram sendo progressivamente transferidos para o "Programa de Controle da Doença de Chagas", que na ocasião fazia parte da Superintendência de Campanhas de Saúde Pública (SUCAM/Ministério da Saúde). Antes disso, o mesmo havia ocorrido no estado de São Paulo, que atuava independentemente do governo federal no controle das chamadas endemias rurais. Aí, já entre 1963-64 o então "Serviço de Erradicação da Malária e Profilaxia da Doença de Chagas do Estado de São Paulo (SEMPDC)" assumia com maior vigor e prioridade o controle vetorial da infecção chagásica.

A informação até então reunida, quando do redimensionamento do programa em 1975, era já bastante para que se conhecesse de forma aproximada a área com transmissão domiciliar endêmica no país. No entanto considerando que essa informação era fragmentária, porque produto de diferentes iniciativas e nem sempre comparáveis, era indispensável dispor-se de uma linha de base inicial que orientasse o controle em larga escala. Assim, foram realizados os dois grandes inquéritos nacionais a que já se fez menção.

O inquérito sorológico, por amostragem aleatória estratificada da população geral residente na área rural brasileira, alcançou a todos os municípios existentes segundo a divisão política do país à época, com exceção daqueles do estado de São Paulo. Foram colhidas, em papel-filtro, mais 
de 1,6 milhão de amostras de sangue, processadas por imunofluorescência indireta (RIFI). A Figura 2.1 seguinte exibe os dados das estimativas de prevalência por estado e para o país (4,2\%).

Em relação àqueles estados com maior soro-prevalência, com taxas superiores à média nacional, os resultados foram, em função do conhecimento já acumulado, não mais do que confirmatórios (Rio Grande do Sul, Minas Gerais, Goiás e Bahia). Alguns outros resultados devem ser vistos criticamente, especialmente pela intensa migração interna que na ocasião se verificava, em direção às regiões centro-oeste e norte, além da crescente urbanização do país.

A distribuição etária dos casos, conforme se mostra na Tabela 2.1 a seguir, revelou haver transmissão ativa em níveis importantes, como está evidenciado pelo fato de que no grupo de idade de 1 a 4 anos de idade foram 2,21 \% os casos soropositivos, ou mesmo como a proporção de soros reativos no grupo até 14 anos, da ordem de $12,86 \%$.

Por outra parte, a grande concentração de casos com reação sorológica positiva na população maior de 15 anos de idade evidenciava o grande acúmulo de infectados resultante da transmissão hiperendêmica da doença de Chagas em anos passados, não obstante se contar há mais de 25 anos com meios eficientes de controle da transmissão vetorial.

6

4

3

2

1

0

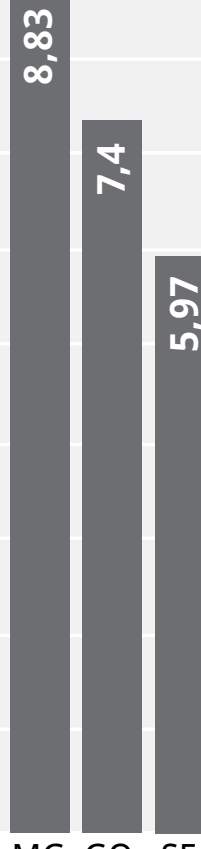

RS MG GO SE
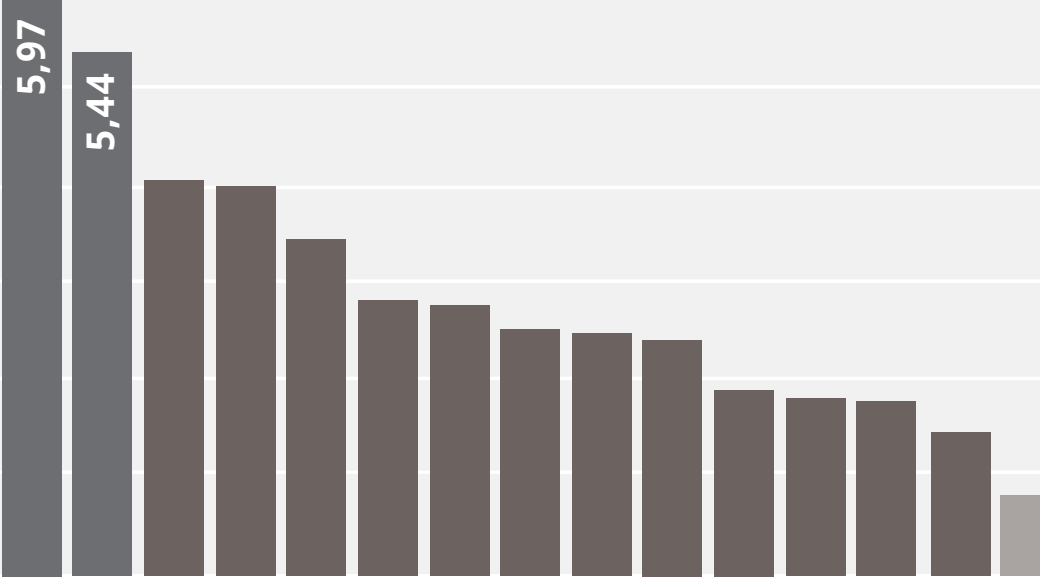

Figura 2.1: Soro prevalência da infecção chagásica. Inquérito Sorológico Nacional. Brasil. 1975/80.

Distribuição por estado. proporção de

2,21

12,86

17,07

12,18

0,02

Modificado de Camargo et al. (1984).

soro-reagentes
Tabela 2.1: Inquérito Sorológico Nacional. Brasil. 1975/80. grupo de idade (referida ou presumida) e proporção observada de ignorado Distribuição percentual dos indivíduos examinados segundo examinados

17,75

0,04

\begin{tabular}{ccc} 
Grupo etário & $\begin{array}{c}\text { \% indivíduos } \\
\text { examinados }\end{array}$ & $\begin{array}{c}\text { proporção de } \\
\text { soro-reagentes }\end{array}$ \\
\hline $1-4$ & 11,08 & 2,21 \\
$5-14$ & 35,90 & 12,86 \\
$15-29$ & 23,78 & 13,26 \\
$30-49$ & 17,75 & 17,07 \\
50 e mais & 11,45 & 12,18 \\
ignorado & 0,04 & 0,02 \\
\hline
\end{tabular}
. 
O inquérito entomológico se fez por busca direta casa a casa, entre 1975 e 1983, já como parte da rotina de operações do programa de controle. A princípio foram investigados 1.942 municípios, em 18 estados e mais o Distrito Federal, sendo que em 1.854 foram encontrados triatomíneos domiciliados $(95,4 \%)$, com a captura de 30 diferentes espécies de vetor (Silveira et al. 1984). Essa área correspondia àquela que se sabia ou presumia infestada,
Tabela 2.2: Número de exemplares de triatomíneos capturados positivos para Trypanosoma sp. (tipo cruzi) e taxas de infecção natural nos levantamentos entomológicos de base (Inquérito triatomínico). 1975-1983.

NÚMERO DE EXEMPLARES

\begin{tabular}{ccccc}
\hline Gênero e espécie & Capturados & Examinados & Positivos & \% Positividade \\
Triatoma sordida & 189.260 & 97.595 & 2.222 & 2,3 \\
$\begin{array}{c}\text { Triatoma infestans } \\
\text { Panstrongylus }\end{array}$ & 162.136 & 92.551 & 8.079 & 8,7 \\
$\quad \begin{array}{l}\text { megistus } \\
\text { Triatoma }\end{array}$ & 149.248 & 114.155 & 3.988 & 3,5 \\
$\begin{array}{c}\text { pseudomaculata } \\
\quad \text { Triatoma }\end{array}$ & 125.634 & 85.950 & 1.481 & 1,7 \\
brasiliensis & 99.845 & 57.983 & 3.904 & 6,7 \\
$\quad$ Outras & 26.900 & 22.523 & 55 & 0,2 \\
$\quad$ Total & 753.023 & 470.757 & 19.729 & 4,2 \\
\hline & & & & Fonte: SUCAM/ MS
\end{tabular}
com um total de aproximadamente 3,6 milhões de $\mathrm{Km}^{2}$, ou $36 \%$ do território nacional. As pesquisas foram posteriormente expandidas, até alcançar um total de 2.493 municípios distribuídos naqueles mesmos 18 estados (Moncayo \& Silveira 2009). Esse total, atualizado com base nas emancipações havidas e segundo a divisão política de 1991, ano em que foi inaugurada a "Iniciativa dos Países do Cone Sul" (INCOSUL/Chagas), e que por isso interessava fazê-lo, constituíam já 3.372 municipalidades (IBGE 1991). Esse espaço geográfico compreendia regiões e estados densamente povoados, o que explica o fato de reunir a maior parte dos municípios brasileiros, ainda que equivalente a não mais do que 36 \% do país em termos territoriais. A Amazônia, naquele momento considerada indene para a doença de Chagas, ou ao menos sem evidencias de transmissão domiciliar, não foi incluída no inquérito.

Conforme se mostra na Tabela 2.2, com base na frequência de capturas feitas, taxas de infecção dos vetores e colonização, cinco foram as espécies identificadas como responsáveis pela transmissão domiciliar, tal como já mencionado. Por ordem de importância: Triatoma infestans, Panstrongylus megistus, T. brasiliensis, T. sordida e T. pseudomaculata.

Em relação a dispersão de cada uma dessas espécies vetoras (Figuras 2.2 e 2.3 e Tabela 2.3) interessa observar que:

$1^{\circ}$. Triatoma infestans, espécie alóctone, cuja distribuição geográfica tinha como limite setentrional de disseminação o sul do Estado de Minas Gerais nos anos 50,

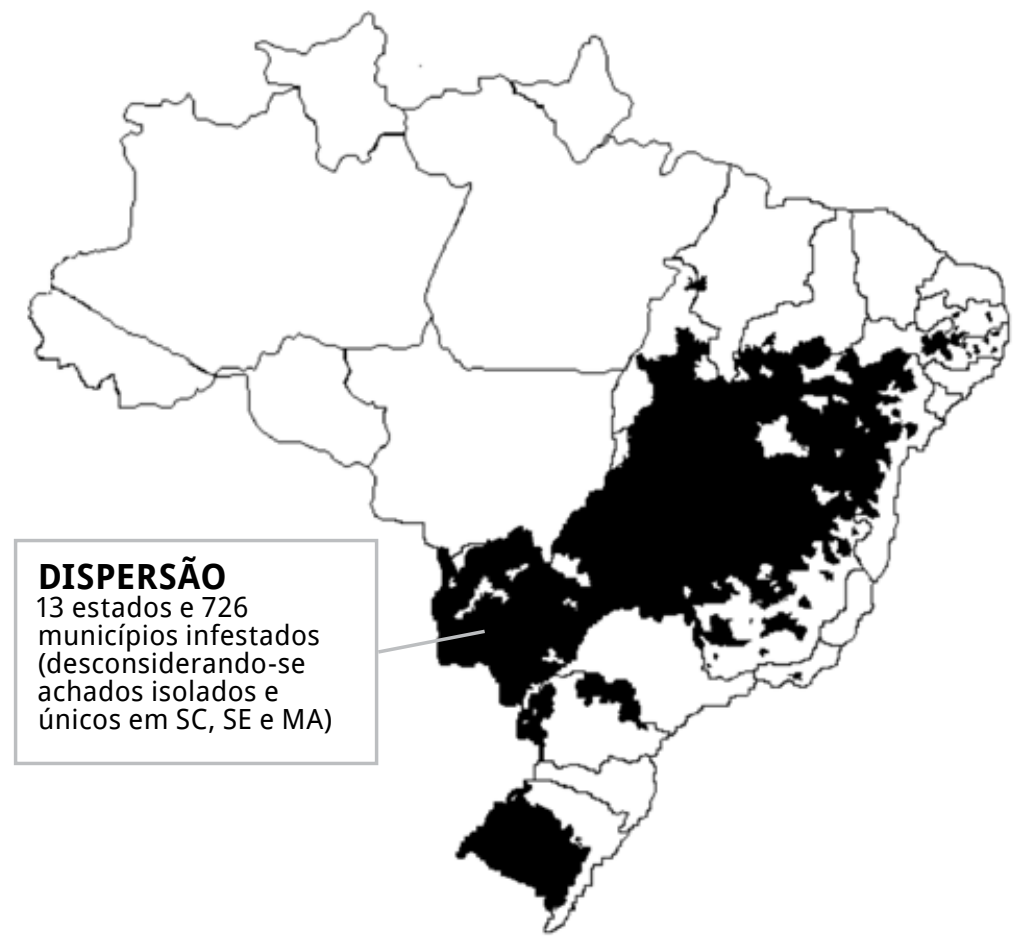

Figura 2.2: Área de dispersão de Triatoma infestans. Brasil. Levantamento entomológico de base (situação "inicial"). 1975-1983. Fonte: Silveira et al. (1984) 
havia sido agora identificado até o sul do Piauí e, no centro-norte do país, nos estados de Mato Grosso e Tocantins (naquela ocasião ainda parte de Goiás);

$2^{\circ}$. entre as espécies autóctones havia uma divisão bastante clara de território, sendo Triatoma sordida espécie própria do domínio dos cerrados, enquanto Triatoma brasiliensis e Triatoma pseudomaculata tinham como centro de endemismo o semiárido do nordeste, ainda que aquela última fosse bastante mais dispersa;

$3^{\circ}$. Panstrongylus megistus era a espécie com mais ampla distribuição, presente em todos os estados cobertos pelas atividades de pesquisa domiciliar.

A partir desses levantamentos iniciais foi definida a área com ris-
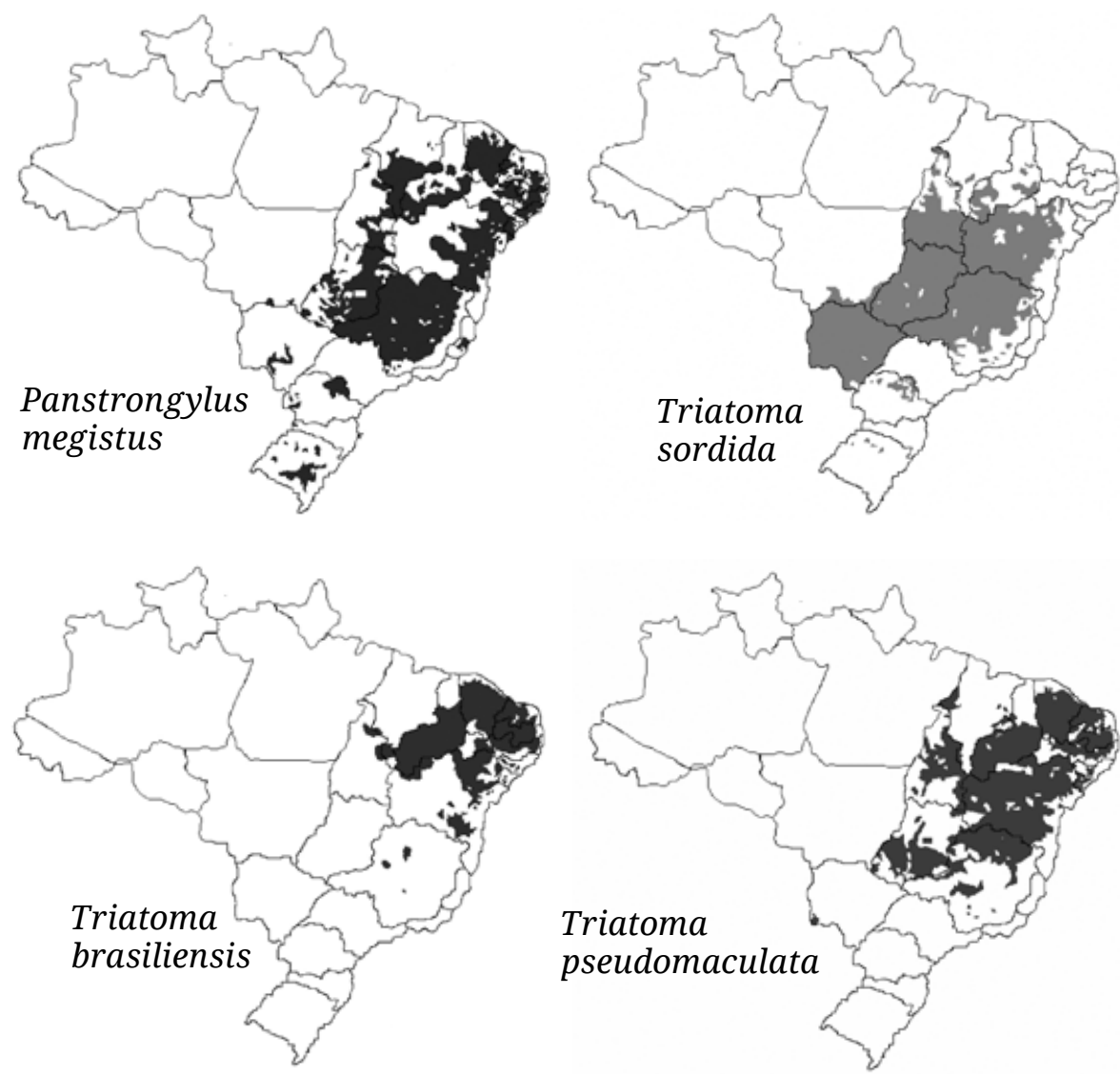

Figura 2.3: Área de dispersão de espécies autóctones consideradas epidemiologicamente mais importantes. Levantamento entomológico de base (situação “inicial”). 1975-1983. Fonte: Silveira et al. (1984). co de transmissão vetorial, e que deveria ser objeto das intervenções de controle. A metodologia de trabalho foi também revista e sistematizada naquela ocasião (1975 e anos imediatamente seguintes), garantindo a necessária continuidade das ações e intervenções em áreas sempre adjacentes e progressivamente crescentes. O controle foi basicamente químico, com o expurgo extensivo com inseticidas de ação residual das localidades infestadas, nos dois ciclos iniciais de operação, e com um intervalo de seis meses a um ano entre eles. A esse "ataque estendido" se seguia o tratamento seletivo de unidades domiciliares ainda positivas, conhecidas por pesquisa domiciliar prévia realizada naquelas localidades que se mostraram infestadas nos ciclos anteriores, suas limítrofes e uma amostra de localidades antes dadas como negativas. Até 1982 o inseticida empregado foi o heclorobenzeno (BHC), a partir de quando foram introduzidos os piretróides de síntese, o que representou um grande avanço, em termos de eficácia, como também em função de sua menor toxicidade para o ser humano e animais domésticos. O ganho em eficácia se deveu antes de tudo à sua ação insetífuga, além de inseticida, pelo desalojamento dos insetos.

Tabela 2.3: Dispersão das principais espécies transmissoras da doença de Chagas capturadas nos levantamentos entomológicos de base entre 1975-1983.

Municípios com captura domiciliar da espécie (1)

\begin{tabular}{lcc}
\hline Espécie & $\mathbf{N}$ & $\mathbf{\%}^{(2)}$ \\
\hline T. infestans & 726 & 37,4 \\
T. brasiliensis & 484 & 24,9 \\
T. pseudomaculata & 840 & 43,2 \\
T. sordida & 661 & 34,0 \\
P. megistus & 1.300 & 66,9 \\
\hline
\end{tabular}

(1) segundo divisão política então existente. (2) em relação ao número total de municípios investigados: 1.942.

Fonte: Silveira et al. (1984) 


\section{As respostas ao controle}

As respostas ao controle químico foram bastante diversas no caso do vetor introduzido ( $T$. infestans) e de espécies nativas (Silveira \& Máximo 1985). Enquanto para T. infestans a infestação foi sendo progressiva e consistentemente focalizada, as espécies autóctones mantinham sua dispersão inicial, mesmo que as populações fossem sendo reduzidas e as colônias intradomiciliares extintas. Esses resultados eram já esperados, com a eliminação de $T$. infestans em muitas áreas e persistência da infestação por espécies nativas, pela possibilidade de re-invasão das casas desde seus focos naturais e/ou permanência de populações residuais no peridomicílio, onde a ação dos inseticidas se sabia menos duradoura.

Embora tenha-se que examinar com alguma reserva os dados constantes da tabela 2.4, pois não se conhece exatamente a cobertura das ações em um e outro momento, além de se cotejar um dado acumulado (as linhas de base foram construídas ao longo de um período de alguns anos) com aqueles conhecidos em um ano determinado (2007) os números revelam, de forma inquestionável, que o impacto das ações foi notavelmente maior para T. infestans, o que fica especialmente evidente pela participação dessa espécie no total de capturas feitas. A diferença é de tal ordem que não resta qualquer dúvida de que assim ocorreu.

Note-se também que $P$. megistus apresentou resposta próxima à que foi observada para $T$. infestans. Isso se explicaria pelo alto grau de domiciliação da espécie no litoral úmido (zona da mata) no nordeste do país e pela grande degradação da mata atlântica, originalmente aí existente. Não é despropositado se considerar que em muitas áreas seria vetor estritamente domiciliário, como na região do "Recôncavo Baiano".

Sobre as demais espécies nativas importa o registro de que, apesar de sua larga dispersão que ainda, compreensivelmente, se mantém, o risco de transmissão domiciliar por elas foi grandemente reduzido. Em relação a T. brasiliensis e T. pseudomaculata comprovou-se uma importante redução das populações domiciliadas e que o tempo de reposição da colonização intradomiciliar, e de restabelecimento da transmissão, pode ser bastante longo (Silveira et al. 2001a, b). Quanto a T. sordida, reiteradas vezes comprovou-se sua limitada capacidade vetorial, determinada fundamentalmente por sua marcada ornitofilia; o que, por consequência, implica baixas taxas de infecção por $T$. cruzi na espécie (uma vez que as aves são refratárias à infecção) e, ademais, pelas raras ocasiões em que podem colonizar o interior da habitação (Silveira et al. 1993).

Os resultados colhidos absolutamente não desobrigam que se siga exercendo estrita vigilância entomológica que, ao contrário, deverá ser intensificada (Dias 2006). O caráter enzoótico da doença de Chagas faz com que a infecção humana

Tabela 2.4: Número de exemplares de triatomíneos capturados das principais espécies consideradas vetoras domiciliares da doença de Chagas no Brasil, e percentual de participação delas no total de capturas. Dados de base (levantamento Triatomínico) em 2007.

\begin{tabular}{lccccc}
\hline Espécie & \multicolumn{5}{c}{ Exemplares capturados } \\
& Dados de & Base & 2007 & Redução \\
& $N$ & $\%$ & $N$ & $\%$ & DB/2007 (\%) \\
\hline Triatoma sordida & 189.260 & 26,1 & 50.731 & 36,9 & $-73,2$ \\
Triatoma infestans & 162.136 & 22,3 & 205 & 0,2 & $-99,9$ \\
Panstongylus megistus & 149.248 & 20,6 & 3.593 & 2,6 & $-97,5$ \\
Triatoma pseudomaculata & 125.634 & 17,3 & 44.332 & 32,2 & $-64,7$ \\
Triatoma brasiliensis & 99.845 & 13,7 & 38.672 & 28,1 & $-61,2$ \\
Total & 726.123 & & & & \\
\hline
\end{tabular}

Fonte: SUCAM e SVS/MS 
por via vetorial seja sempre possível, ainda que ocorra episódica ou acidentalmente. Além disso, a manutenção das demais formas de transmissão depende primariamente daquela que é naturalmente produzida pela veiculação de T. cruzi pelos vetores, domiciliados ou não.

\section{A situação epidemiológica atual}

A situação epidemiológica atual, não apenas como resultado das atividades de controle, mas também de mudanças estruturais havidas no país, desenvolvimento sócio econômico, com melhoria das condições de habitação; urbanização crescente, com migração das populações rurais para o meio urbano; além de outras condições influentes, foi substancialmente alterada.

Adiante se mostra um conjunto de informações que servem para avaliar o risco atual da transmissão vetorial da doença de Chagas no Brasil.

A cobertura das atividades de vigilância entomológica e controle, não obstante as dificuldades decorrentes da mudança ainda recente do modelo de atuação, com operações descentralizadas de controle nos últimos anos, foi bastante importante tomando por base os dados conhecidos pela Gerência Nacional do Programa, (Secretaria de Vigilância em Saúde do Ministério da Saúde). Os dados constantes da Figura 2.4 revelam que entre os anos 2004 e 2007 foram em média investigadas, aproximadamente 1,7 milhão de unidades domiciliares/ano. Vale observar que os números apresentados não incluem, para alguns estados, as atividades desenvolvidas em um ou outro ano, desde que não há registro delas no nível central nacional, em função de problemas relacionados ao sistema de informação. No período considerado foram promovidos ajustes, nem sempre feitos de forma simultânea pelas Secretarias Estaduais. Isso significa que os dados que aqui se apresentam correspondem ao que se sabe com segurança haver sido efetivamente executado, podendo eventualmente não se contabilizar parte do trabalho realizado.

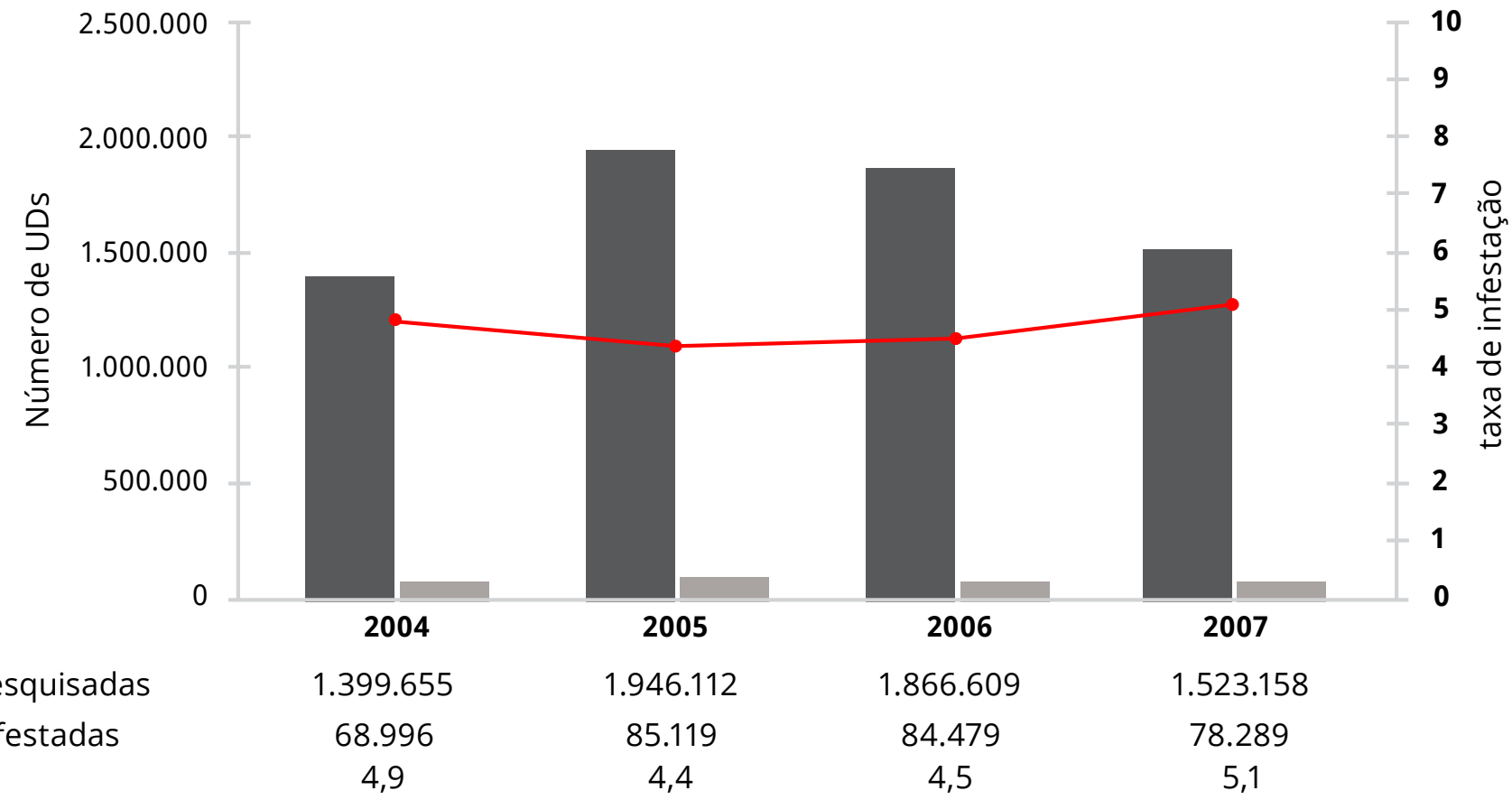

Figura 2.4: Unidades domiciliares (UDs) pesquisadas, infestadas por triatomíneos, conhecidos pela Gerência Nacional do Programa de Controle da doença de Chagas, e taxa bruta de infestação (II). Brasil. 2004-2007. 
As taxas de infestação agregadas por ano e país, e sem estar discriminadas por local de captura e estádio podem não ter maior significação epidemiológica. Incluem infestação estritamente peridomiciliar e por espécies de triatomíneos com pequena ou mínima capacidade vetorial. Efetivamente assim se comprova ser, ao exame das tabelas a seguir (Tabelas 2.5 e 2.6). T. sordida foi a espécie mais frequentemente capturada no período considerado, com aproximadamente 50\% do total de exemplares de triatomíneos coletados em capturas domiciliares e, como antes já referido, $T$. sordida é vetor muito pouco importante na transmissão de $T$. cruzi. Houve também uma alta frequência de capturas de vetores nativos da região nordeste (T. pseudomaculata e T. brasiliensis). T. infestans, principal vetor no passado, especialmente no centro, sul e sudeste do país, contribuiu agora, com dados acumulados de 2004 a 2008, com não mais do que 0,09 do total de espécimes capturados.
Tabela 2.5: Exemplares de triatomíneos capturados por espécie no período 2004 a 2008. Dados acumulados, conhecidos pela Gerência Nacional do Programa de Controle da doença de Chagas.

\begin{tabular}{lcr}
\hline Espécie & Exemplares capturados \\
& $\mathrm{N}$ & $\%$ \\
T. sordida & 307213 & 48,4 \\
T. pseudomaculata & 135642 & 21,4 \\
T. brasiliensis & 130902 & 20,6 \\
P. megistus & 20418 & 3,2 \\
P. lutzi & 10822 & 1,7 \\
R. neglectus & 7184 & 1,1 \\
T. rubrovaria & 4698 & 0,7 \\
R. nasutus & 3557 & 0,6 \\
T. rubrofasciata & 3457 & 0,5 \\
P. geniculatus & 3265 & 0,5 \\
T. infestans & 568 & 0,09 \\
Outras & 7417 & 1,2 \\
Total & 635143 & 100 \\
\hline
\end{tabular}

Fonte: SVS/ Ministério da Saúde
Outro acontecimento significativo, e que deve ser observado, é a emergência de espécies antes consideradas quase estritamente silvestres, ou com achado apenas episódico no ambiente peridomiciliar. Ainda que em alguns casos tenham limitada dispersão em termos geográficos e que não seja conhecida sua competência como vetores da infecção chagásica, demandam atenta vigilância, e investigação no esclarecimento do risco por elas representado, muito especialmente é esse o caso de Panstrongylus lutzi.

A propósito da distribuição geográfica dos vetores (tabela 2.6) importa assinalar que:

1. T. sordida que tem centro de endemismo nos cerrados é a espécie predominante na Bahia e nos estados das regiões sudeste e centro-oeste, incluindo áreas de transição para a Amazônia;
Tabela 2.6: Espécie de triatomíneo com maior frequência de capturas domiciliares por estado com ações regulares de controle vetorial e seu percentual de participação no total de capturas. Dados acumulados para o período de 2004 a 2008.

\begin{tabular}{|c|c|c|}
\hline Estado & $\begin{array}{c}\text { Espécie } \\
\text { predominante }\end{array}$ & $\begin{array}{r}\text { Participação } \\
(\%) \text { no total } \\
\text { de capturas }\end{array}$ \\
\hline Maranhão & Triatoma rubrofasciata & 93,0 \\
\hline Piauí & Triatoma brasiliensis & 59,7 \\
\hline Ceará & Triatoma pseudomaculata & 55,5 \\
\hline Rio Grande do Norte ${ }^{(1)}$ & $\ldots$ & $\ldots$ \\
\hline Paraíba & Triatoma brasiliensis & 71,4 \\
\hline Pernambuco & Triatoma brasiliensis & 44,2 \\
\hline Alagoas & Triatoma pseudomaculata & 50,3 \\
\hline Sergipe & Triatoma pseudomaculata & 41,0 \\
\hline Bahia & Triatoma sordida & 87,6 \\
\hline Minas Gerais & Triatoma sordida & 92,4 \\
\hline Espírito Santo & Triatoma vitticeps & 97,2 \\
\hline São Paulo & Triatoma sordida & 88,8 \\
\hline Paraná (2) & Panstrongylus megistus & $\ldots$ \\
\hline Rio Grande do Sul & Triatoma rubrovaria & 81,1 \\
\hline Goiás & Triatoma sordida & 85,9 \\
\hline Mato Grosso do Sul & Triatoma sordida & 79,7 \\
\hline Mato Grosso & Triatoma sordida & 94,5 \\
\hline Tocantins & Triatoma sordida & 69,6 \\
\hline Brasil & Triatoma sordida & 48,4 \\
\hline
\end{tabular}

(1) os dados conhecidos pela SVS/MS apresentam incongruências que não permitem definir com suficiente segurança a espécie predominante no estado. (2) os dados conhecidos pela SVS/MS não permitem precisar com suficiente segurança a participação (\%) da espécie predominante no total de capturas domiciliares feitas no estado. 
2. o marcado predomínio de $T$. sordida em alguns dos estados antes maciçamente infestados por $T$. infestans e coincidentemente os mais densamente povoados, como Bahia, São Paulo, Minas Gerais e também Goiás (em Minas Gerais o número de exemplares capturados foi equivalente a mais de $90 \%$ das capturas feitas);

3. T. brasilienis e T. pseudomaculata, dividem-se como espécies predominantes nos estados do

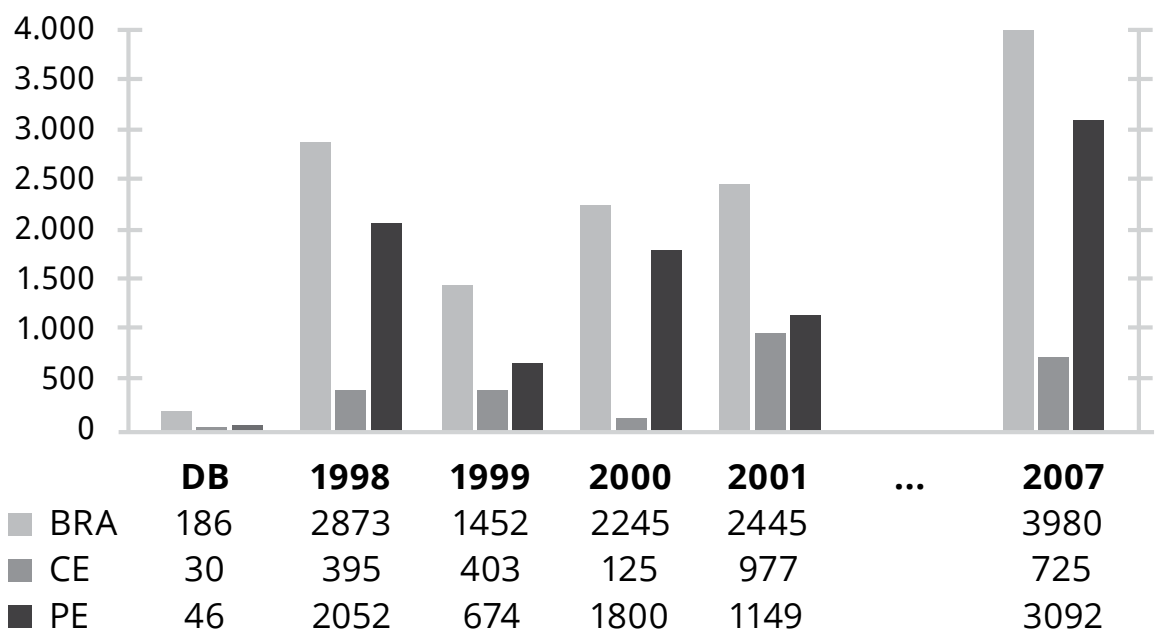

Figura 2.5: Número de exemplares de Panstrongylus lutzi capturados no Brasil e estados do Ceará e Pernambuco. 1975-83, Dados de Base (DB), 1998, 1999, 2000, 2001 e 2007. Fonte: SES CE e PE; SVS/MS. nordeste;

4. T. vitticeps no Espírito Santo e T. rubrofasciata no Maranhão são espécies quase exclusivas, ao menos nas áreas que vem sendo cobertas;

5. Rio Grande do Sul, ainda que haja um expressivo predomínio de capturas de T. rubrovaria, o achado de $P$. megistus não é infrequente;

Os resultados das atividades cumpridas, ratificam assim o baixo risco de transmissão vetorial naquela área originalmente endêmica, a través do vetor domiciliado e colonizando o interior das habitações.

De forma sumária, assumindo que os dados disponíveis oferecem suficiente confiabilidade, se poderia afirmar que atualmente:

1. a transmissão por Triatoma infestans é improvável, mesmo nos poucos focos remanescentes, pela baixíssima infestação e densidade das populações existentes (foi formalmente certificada sua interrupção, no ano de 2006, por Comissão Intergovernamental dos Países do Cone Sul e OPAS/OMS);

2. a transmissão domiciliar por aquelas espécies autóctones que quando dos levantamentos de base se admitia terem participação direta na produção de casos humanos da infecção é possível, mas não com a frequência ou nos níveis de alta endemicidade em que ocorria, sobretudo no caso de Panstrongylus megistus.

Entre as muitas outras espécies de triatomíneos nativas duas em particular devem ser objeto de atenção, pela frequência com que têm sido capturadas em anos recentes e pela sua tendência, já há algum tempo demonstrada, à constituição de colônias no interior dos domicílios. Tratam-se de Triatoma rubrovaria (Silveira et al. 1998, Almeida et al. 1999) no estado do Rio Grande do Sul e Panstrongylus lutzi, na região Nordeste, em especial nos estados do Ceará e de Pernambuco (Figura 2.5). Registre-se ainda que $P$. lutzi apresenta altas taxas de infecção por T. cruzi (Silveira \& Feitosa 1984).

No caso de Triatoma rubrovaria, espécie que no país tem distribuição limitada ao Rio Grande do Sul, claramente esse processo se deveu, ou acompanhou, a gradual eliminação de $T$. infestans no centro-sul daquele estado (Figura 2.6). Note-se que desde o ano de 1983 houve uma inversão no 
número de exemplares capturados de uma e outra espécie.

Com a grande diversidade de situações existentes no país e diferente risco de transmissão, ou de restabelecimento da transmissão vetorial domiciliar, se instituiu a partir de 2006 o enfoque de risco na definição de prioridades em termos de área de atuação (SVS/Ministério da Saúde 2005), com a adoção de ações de vigilância e controle que fossem a ele proporcionais. A estratificação feita, com

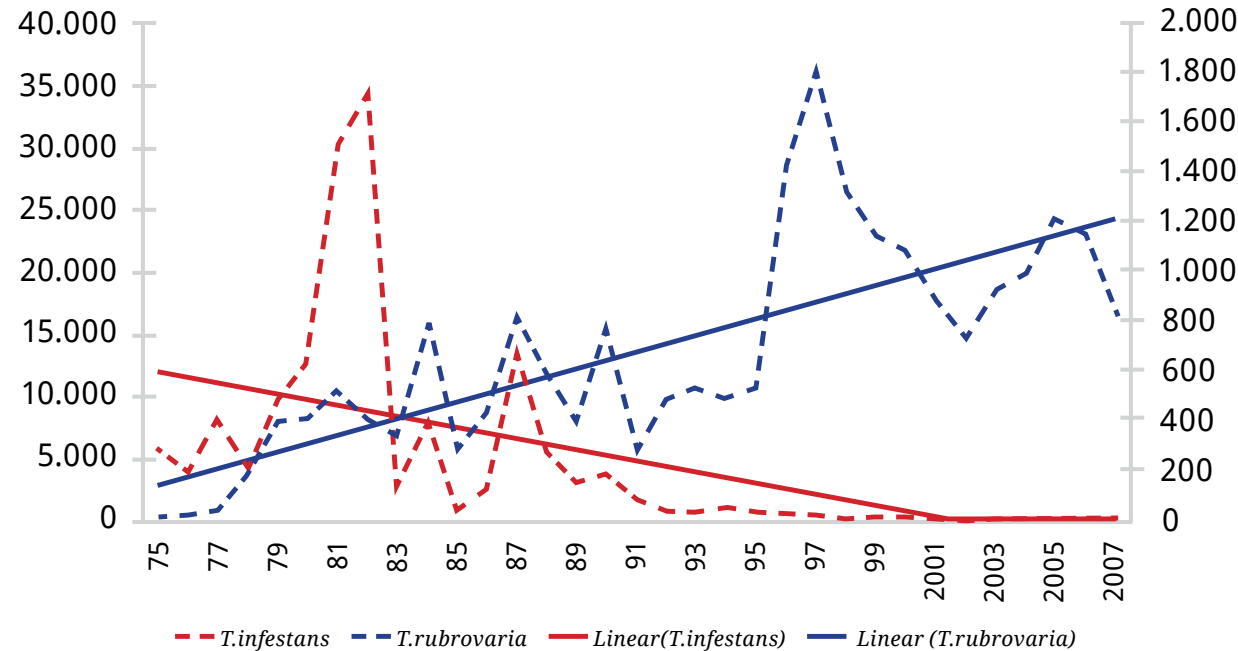

Figura 2.6: Exemplares de Triatoma infestans e Triatoma rubrovaria capturados no estado do Rio Grande do Sul, Brasil. 1975/2007. Fontes: SUCAM, FUNASA e SVS/MS; SES/RS.

base em diferentes variáveis, não apenas entomológicas (Silveira 2004), levou ao mapeamento das áreas (municípios) conforme se mostra na Figura 2.7.

Ao todo 2.956 municípios foram distribuídos em estratos de alto, médio e baixo risco. Na maior parte o risco existente é o de reinfestação com colonização intradomiciliar, e não propriamente de transmissão. Ou seja, de uma condição anterior necessária ao restabelecimento da transmissão domiciliar.

Importa assinalar que entre os municípios considerados de alto risco estão aqueles ainda infestados por T. infestans, por menores que sejam as populações remanescentes, ou recente que seja a história de infestação pela espécie.

À medida que a transmissão vetorial endêmica foi sendo controlada, basicamente pela aplicação domiciliar de inseticidas, outros mecanismos de transmissão passaram a assumir maior importância do ponto de vista epidemiológico. A princípio creditou-se às vias transfusional e congênita a manutenção da endemia chagásica, que progressivamente tenderiam também ao esgotamento, desde que o mecanismo primário, vetorial, já não produziria novos casos da infecção, a não ser episodicamente. A possibilidade de controle eficaz da transmissão por transfusão sanguínea, pela triagem de candidatos à doação de sangue através de provas sorológicas de alta sensibilidade, foi confirmada e viabilizada na prática pelo grande aumento da cobertura em bancos de sangue. Para isso contribuiu a implementação dessas ações a partir da epidemia de HIVIAIDS. A transmissão congênita, ainda que inevitável em termos de prevenção primária, sempre

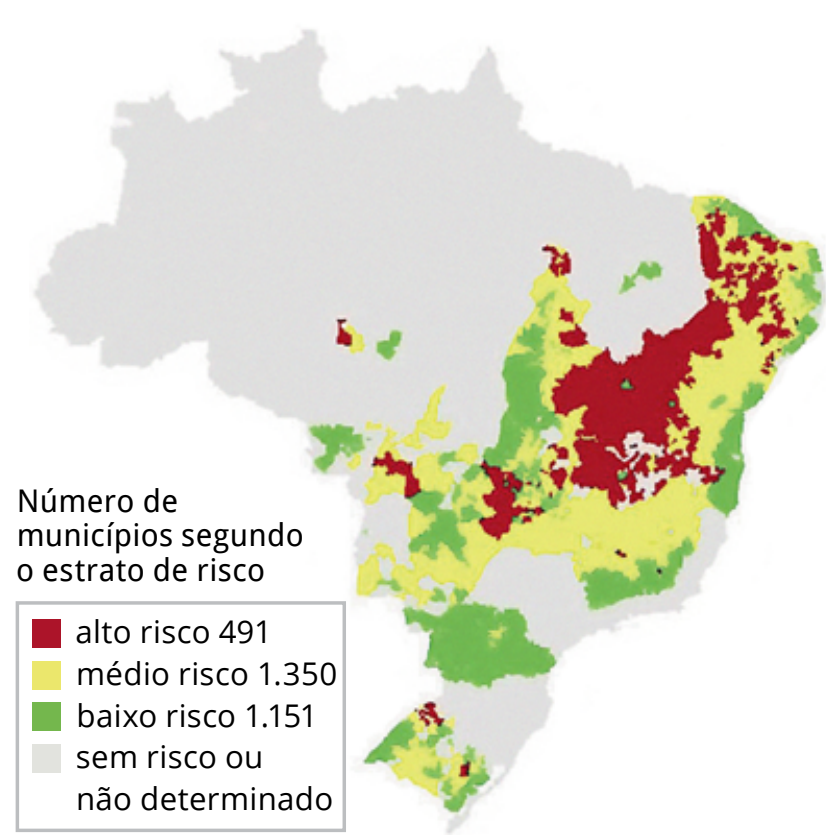

Figura 2.7: Distribuição dos municípios brasileiros conforme estratificação de risco de transmissão vetorial da doença de Chagas ou de restabelecimento da transmissão domiciliar. 2006. Fonte: SVS/MS. 
mostrou diferenças regionais importantes e, no caso do Brasil, de modo geral, menor relevância do que aquela conhecida em outros países. Ainda assim casos ocorrerão mais ou menos frequentemente, enquanto houver mulheres em idade fértil infectadas.

Mecanismos excepcionais de transmissão, de caráter fortuito, seriam aqueles associados à enzootia chagásica, incluídas a via oral e a vetorial extra domiciliar, ou ainda por "visitação" de vetores silvestres aos domicílios. Essas seriam formas de transmissão raras e quase inevitáveis, porque pouco previsíveis. Com respeito à transmissão oral é de se registrar que por longo tempo foi questionada sua viabilidade, desde quando reportados os primeiros casos (Nery-Guimarães et al.1968); ainda que, entre reservatórios animais, tanto silvestres como domésticos, houvesse sido repetidas vezes reportada (Mayer \& Rocha Lima 1914, Dias 1933 e 1940, Talice 1944, Diaz-Ungria 1965).

Com a virtual interrupção da transmissão vetorial domiciliar no país, no caso de $T$. infestans, o mais importante vetor, comprovada e formalmente certificada e, a partir do primeiro registro de casos autóctones agudos feitos para a região amazônica (Shaw et al. 1969), em que era aventada a possibilidade de transmissão oral, foram sendo reunidas muitas evidencias de sua ocorrência na Amazônia. Da mesma forma outros tantos episódios foram sendo conhecidos na área extra-amazônica, quase sempre na forma de surtos entre comensais ou com fonte comum de infecção (Shikanai-Yasuda et al. 1991, Ministério da Saúde 2005a, Gontijo \& Santos 2009).

A enzootia chagásica na Amazônia desde há muito era conhecida. O próprio Carlos Chagas pode comprová-la, tendo inclusive isolado T. cruzi, de macacos da espécie Saimiri scirius no estado do Pará (Chagas 1924). Muitos reservatórios animais foram sendo aí identificados (Deane 1961 e 1964, Valente \& Valente 1996a), assim como diversas espécies de triatomíneos. Ao menos 18 espécies haviam sido assinaladas na região até o inicio da década de 90 , das quais 10 naturalmente infectadas (Coura et al. 1994). No entanto, a inexistência de triatomíneos domiciliados, por longo tempo fez crer que a transmissão em níveis endêmicos da doença de Chagas era improvável.

Mesmo que não haja ainda evidências documentadas de domiciliação de triatomíneos, a não ser de Triatoma maculata em Roraima (Luitgards-Moura 2005 e Ministério da Saúde 2005b) e de forma incipiente de Panstrongylus geniculatus na região de Marajó, Pará (Valente \& Valente 1996a), o número crescente, a ocorrência reiterada e o grande acúmulo de casos de doença de Chagas aguda na região representam elementos suficientes para que se possa considerar hoje a doença de Chagas endêmica em parte da Amazônia brasileira.

O que é certo é que se reconhece hoje no país três diferentes áreas do ponto de vista da epidemiologia da enfermidade de Chagas, ou três diferentes espaços eco-epidemiológicos e de transmissão de T. cruzi (Figura 2.8): i) a área extra-amazônica, inicialmente endêmica, com transmissão domiciliar, que foi por longo tempo objeto de ações sistematizadas de controle vetorial e

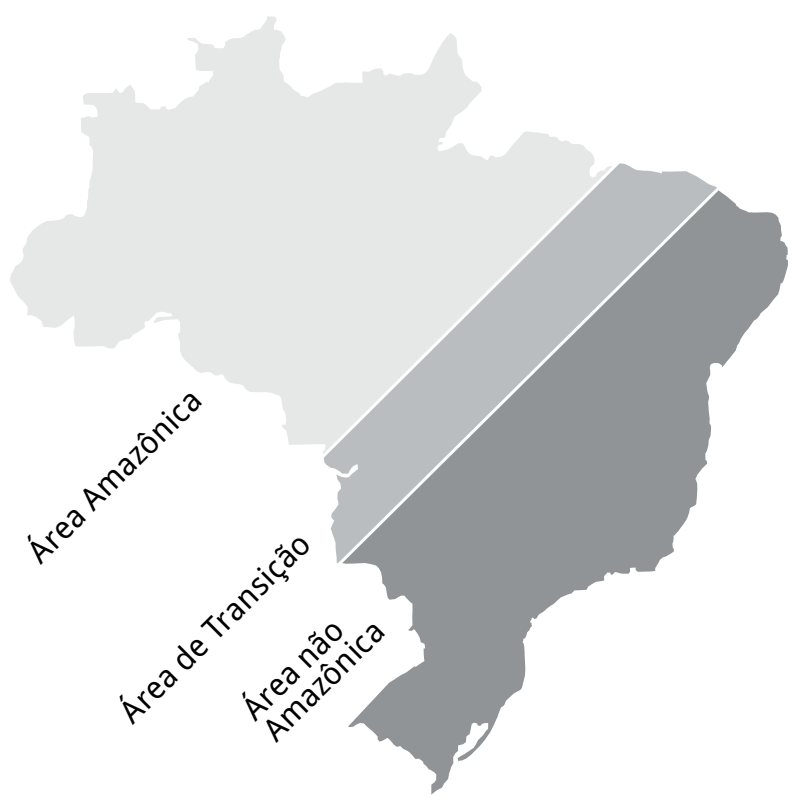

Figura 2.8: Diferentes cenários eco-epidemiológicos e de padrões de transmissão da doença de Chagas no Brasil. 2009. Fonte: SVS/Ministério da Saúde. 
onde, atualmente, ocorre transmissão residual por diferentes espécies nativas, entre as quais teriam especial importância T. brasiliensis e T. pseudomaculata na região nordeste; ii) a área amazônica, em que a endemia chagásica é sustentada por mecanismos antes considerados extraordinários de transmissão: oral, extra domiciliar e domiciliar sem colonização vetorial (Silveira 2006); e iii) uma área de transição em que coexistem os dois cenários e que abrange os estados do Maranhão, Tocantins e Mato Grosso.

A emergência da doença de Chagas na Amazônia não é de fato um acontecimento novo, no sentido de que apenas recentemente teria passado a ocorrer a infecção humana autóctone. $\mathrm{O}$ que parece sim ter havido foi uma maior visibilidade, decorrente por um lado dos agora baixos níveis de transmissão na área originalmente endêmica e, por outro, da implementação das ações de vigilância naquela região.

Em revisão da casuística da doença de Chagas feita por profissionais do Instituto Evandro Chagas em 2004 (Silveira e Santos 2005 apud Valente et al. 2004), que até então reunia praticamente toda a informação existente sobre a enfermidade na região amazônica, como mostram diferentes publicações de pesquisadores daquela instituição (Frahia et al. 1995, Valente et al. 1999), eram contabilizados: 416 casos autóctones com média de 16 casos/ano; 5 casos crônicos; 411 casos agudos com 11 óbitos; 285 (69,34\%) casos agudos relacionados com "microepidemias" (ME); 59 ME, com média de 4,68 casos por episódio.

Em que pese os esforços para a implantação de vigilância epidemiológica regular e sistematizada junto aos serviços de saúde (Feitosa 1995, Valente et al. 1995), o não reconhecimento da importância da enfermidade na região e o desconhecimento sobre ela existente, além da alta prevalência de patologias como malária e hanseníase entre outras, contribuíram para que a doença de Chagas, em alguma medida e por algum tempo, fosse negligenciada como problema de saúde pública na Amazônia. Como alternativa estratégica, que viabilizou de inicio as atividades em larga escala da vigilância de $T$. cruzi na Amazônia, buscou-se associar a vigilância da doença de Chagas àquela já exercida para malária, a partir da capacitação de microscopistas que atuavam no programa de controle dessa parasitose.

Com isso e com o fato de que o diagnóstico de doença de Chagas era cada vez mais frequente em algumas áreas, especialmente no estado do Pará, em Belém e municípios próximos, houve um grande incremento no número de casos registrados a partir de 2006. Isso se comprova pelo exame dos dados constantes da Tabela 2.7 em que se exibe o número de casos de doença de Chagas Aguda (DCA) conhecidos na Amazônia Legal do Brasil, que inclui os estados do Maranhão e do Mato Grosso, e o total de óbitos registrados na região entre 2005 e 2008.

Tal como antes assinalado, a participação do estado do Pará no número total de casos é extraordinariamente alta, contribuindo com $76 \%$ dos casos conheci-

Tabela 2.7: Número de casos de Doença de Chagas Aguda (DCA) conhecidos na Amazônia Legal do Brasil e total de óbitos registrados no período 2005 a 2008.

\begin{tabular}{lcccccr}
\hline Estado & \multicolumn{5}{c}{ Número de casos / ano } & Óbitos \\
& 2005 & 2006 & 2007 & 2008 & Total & \\
\hline Amazonas & & & 28 & & 28 & 1 \\
Pará & 10 & 83 & 109 & 99 & 301 & 12 \\
Amapá & & 5 & 19 & 20 & 44 & \\
Tocantins & & & 1 & 5 & 6 & \\
Maranhão & 2 & 1 & 2 & 5 & 10 & 1 \\
Mato Grosso & & 1 & 1 & & 2 & \\
Brasil & 12 & 90 & 160 & 129 & 391 & 14 \\
\hline \multicolumn{7}{l}{} \\
& & \multicolumn{5}{c}{ Fonte: SVS/Ministério da Saúde }
\end{tabular}


dos no período considerado (Figura 2.9).

Fato notável é que na medida em que se passou a atentar para a ocorrência de doença de Chagas com transmissão por via oral na região amazônica, outros tantos episódios, na forma de surtos localizados, foram reportados para a região extra-amazônica, enquanto antes disso foi acontecimento raramente verificado. Além do mais, casos agudos isolados de transmissão vetorial por visitação e ainda outros em que não se pode comprovar o mecanismo responsável pela produção dos casos foram notificados.

A Tabela 2.8 mostra que afora os $391 \mathrm{ca}$ sos de DCA registrados para a Amazônia Legal, outros 53 foram conhecidos em estados de outras macroregiões, entre 2005 e 2008, o que totaliza 444 casos para o país naquele período.

A distribuição conforme o mecanismo de transmissão (Tabela 2.9) revela que a grande maioria deles foi devida, ou atribuída, à via oral, que representou aproximadamente 74 $\%$ do total de casos.

Desse modo resulta muito evidente que a atual situação epidemiológica da doença de Chagas no Brasil se caracteriza pela: i) ascendência e predomínio da transmissão diretamente relacionada à enzootia chagásica, especialmente pela via oral, em que a infecção humana não deixa de ser acidental, por mais frequente que possa ser; e, ii) pela concentração de casos na região amazônica, especialmente na forma de surtos localizados, e que tem experimentado um grande incremento desde quando instituídas ações regulares de vigilância (Figuras 2.10 e 2.11).

Interessa notar que na Amazônia a distribuição dos casos autóctones de enfermidade de Chagas aguda é muito desigual. Há que distinguir: i) áreas com transmissão endêmica; ii) áreas em que casos são conhecidos epi-

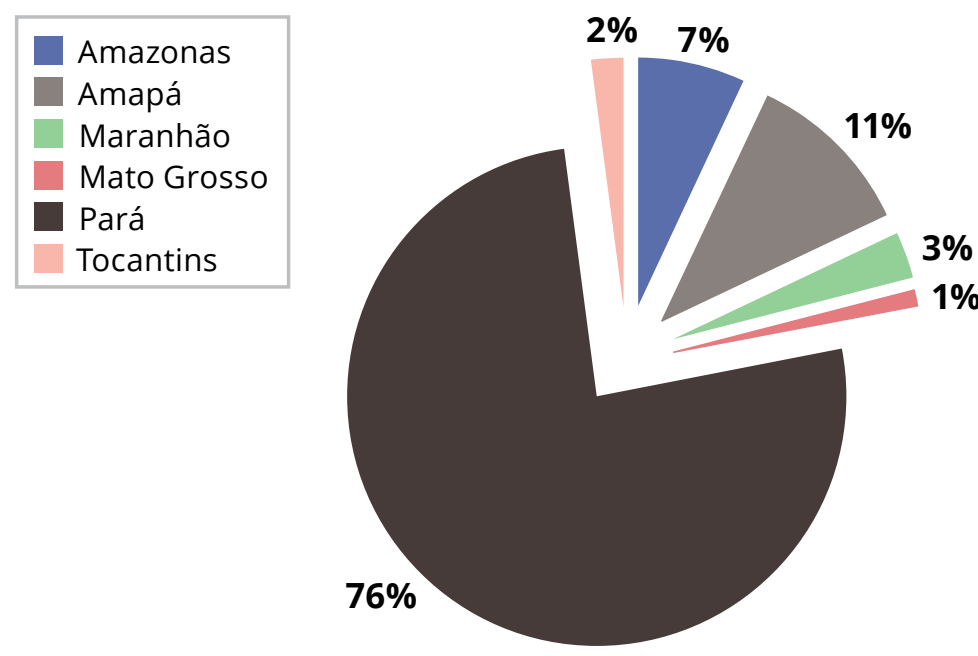

Figura 2.9: Participação (\%) dos estados da Amazônia Legal Brasileira no número total acumulado de casos de Doença de Chagas Aguda na região, no período 2005 a 2008.

Fonte: SVS/Ministério da Saúde.

Tabela 2.8: Número de casos de Doença de Chagas Aguda (DCA) conhecidos no Brasil e total de óbitos registrados no período 2005 a 2008.

\begin{tabular}{lcccccr}
\hline Estado & \multicolumn{5}{c}{ Número de casos/ ano } & Óbitos \\
& 2005 & 2006 & 2007 & 2008 & Total & \\
\hline Amazonas & & & 28 & & 28 & 1 \\
Pará & 10 & 83 & 109 & 99 & 301 & 12 \\
Amapá & & 5 & 19 & 20 & 44 & \\
Tocantins & & & 1 & 5 & 6 & \\
Maranhão & 2 & 1 & 2 & 5 & 10 & 1 \\
Piauí & & 2 & 1 & 1 & 4 & \\
Ceará & & 8 & & 1 & 9 & \\
Bahia & & 13 & & & 13 & 2 \\
São Paulo & & 3 & & & 3 & 1 \\
Santa Catarina & 24 & & & & 24 & 3 \\
Mato Grosso & & 1 & 1 & & 2 & \\
Brasil & 36 & 116 & 161 & 131 & 444 & 20 \\
\hline & \multicolumn{5}{c}{ Fonte: SVS/Ministério da Saúde }
\end{tabular}

Tabela 2.9: Casos de Doença de Chagas Aguda (DCA) conhecidos no Brasil, segundo o mecanismo de transmissão.

\begin{tabular}{lccccccc}
\hline Ano & $\begin{array}{c}\text { N. Total } \\
\text { de casos }\end{array}$ & \multicolumn{4}{c}{$\begin{array}{c}\text { Casos segundo o mecanismo } \\
\text { de transmissão }\end{array}$} \\
& & \multicolumn{2}{c}{ Oral } & \multicolumn{3}{c}{ Vetorial } & \multicolumn{3}{l}{ Ignorado } \\
& & $\mathrm{N}$ & $\%$ & $\mathrm{~N}$ & $\%$ & $\mathrm{~N}$ & $\%$ \\
\hline 2005 & 36 & 27 & 81,8 & 0 & 0 & 9 & 25,0 \\
2006 & 116 & 107 & 90,7 & 3 & 2,5 & 6 & 5,2 \\
2007 & 161 & 119 & 73,9 & 3 & 1,8 & 39 & 24,2 \\
2008 & 131 & 74 & 56,5 & 4 & 3,2 & 53 & 40,4 \\
Total & 444 & 327 & 73,8 & 10 & 2,3 & 107 & 23,9 \\
\hline
\end{tabular}

Fonte: SVS/Ministério da Saúde 
sodicamente; e, iii) áreas sem transmissão conhecida ou para as quais não existe informação.

Uma vez que se considere os estados que compõem a região amazônica, se poderia categorizá-los de acordo com a situação antes descrita em: grupo 1: Amazonas, Amapá e Pará; grupo 2: Maranhão, Mato Grosso e Tocantins; grupo 3: Acre, Rondônia e Roraima.

O primeiro grupo corresponde a estados em que se está fazendo a busca sistematizada e em ampla escala de T. cruzi em lâminas coletadas para o diagnóstico de malária, e onde há a ocorrência frequente de casos, particularmente no estado do Pará. O segundo grupo inclui aqueles estados que se poderia considerar de transição entre o cerrado e a floresta amazônica e, daí, apresentarem como peculiaridade comum entre eles, o fato de serem áreas em que havia a transmissão domiciliar endêmica e que registram agora casos com o "padrão amazônico" de transmissão. Têm apresentado apenas episodicamente casos de DCA. Por fim, para o último grupo de estados não há informação. A vigilância da doença de Chagas não foi instalada como atividade rotineira, o que pode significar que simplesmente não existe transmissão ou que não se atribui a ela, na prática, qualquer importância.

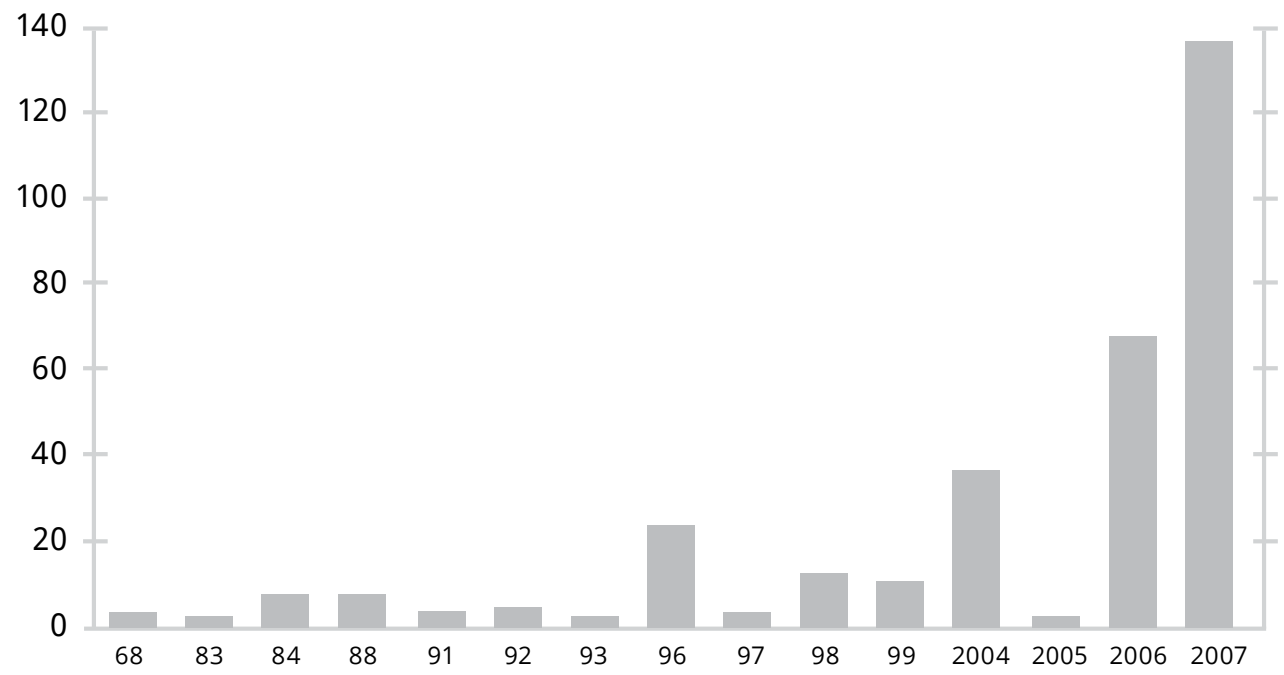

Figura 2.10: Número de casos de Doença de Chagas aguda em surtos registrados na Amazônia brasileira. 1968/2007.

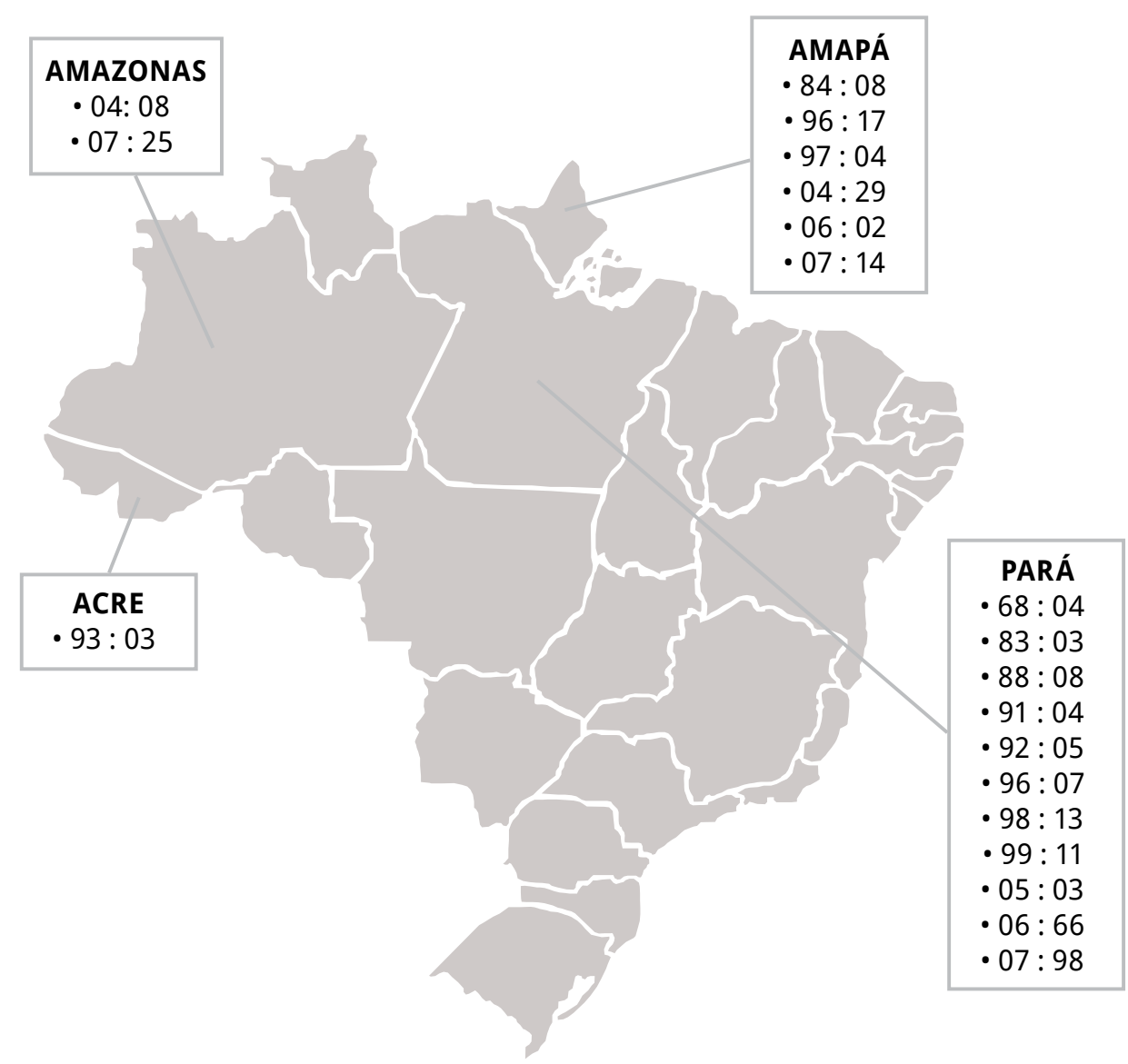

Figura 2.11: Número de casos de Doença de Chagas Aguda (DCA) relacionados a surtos, registrados por estado e ano na Amazônia brasileira. 1968 - 2007. Fonte: Gerência Técnica de Doença de Chagas/ SVS/Ministério da Saúde 
Em escala de município, o quadro seguinte (Figura 2.12) revela que poucos são os municípios que apresentaram ao longo do tempo notificação reiterada de enfermidade aguda na Amazônia. Esse fato pode significar que essa área é aquela de maior risco e onde se concentra a transmissão endêmica da infecção/doença de Cha-

\begin{tabular}{|c|c|c|c|c|c|c|c|c|c|c|c|c|c|c|c|}
\hline \multirow{2}{*}{ Estado } & \multirow{2}{*}{ Município } & \multicolumn{14}{|c|}{ Anos } \\
\hline & & 68 & 83 & 84 & 88 & 91 & 92 & 96 & 97 & 98 & 99 & 04 & 05 & 06 & 07 \\
\hline \multirow{2}{*}{ Amapá } & Macapá & & & a & & & & & & & & & & $\mathbf{a}$ & 口 \\
\hline & Santana & & & & & & & & $\mathbf{\square}$ & & & $\mathbf{\square}$ & & 口 & \\
\hline Amazonas & Tefé & & & & & & & & & & & $\mathbf{\square}$ & & 口 & \\
\hline \multirow{6}{*}{ Pará } & Abaetetuba & & & & & & & & & $\mathbf{\square}$ & & & 口 & 口 & \\
\hline & Ananindeua & & & & & & & & & & & & 口 & 口 & 口 \\
\hline & Barcarena & & & & & & & & & & & & $\mathbf{\square}$ & 口 & 1 \\
\hline & Belém & $\mathbf{\square}$ & [ & & $\boldsymbol{\square}$ & & & $\mathbf{a}$ & & & & & 口 & $\boldsymbol{\square}$ & $\square$ \\
\hline & Cametá & & & & $\boldsymbol{\square}$ & & & & & & & & & & 口 \\
\hline & Santarém & & & & & & & & & & $\boldsymbol{\square}$ & & & च & \\
\hline
\end{tabular}

Figura 2.12: Municípios com ocorrência reiterada de Doença de Chagas Aguda (DCA) na Amazônia. 1968-2007. gas humana. No entanto, considerando que a vigilância epidemiológica na Amazônia não abarca ainda todo seu extenso território, essa afirmação não é possível fazer com absoluta segurança.

\section{O futuro: novos desafios}

Há dois grandes desafios a enfrentar. O primeiro deles é sustentar os níveis de controle alcançados na transmissão vetorial domiciliar desde que passou a ser inexistente ou apenas focal, mesmo que em alguns casos possa ser previsível ou provável, quando presentes vetores autóctones de comportamento ubíquo, que persistem em focos silvestres, mas com reconhecida capacidade invasiva e de colonização do ambiente domiciliar. O segundo desafio se refere à necessidade de se conceber e desenvolver modelos de vigilância e controle que possam reduzir o risco de transmissão associado ou diretamente dependente do ciclo silvestre de transmissão. 